\section{BMJ Open Respiratory Research}

\title{
Face mask sampling reveals antimicrobial resistance genes in exhaled aerosols from patients with chronic obstructive pulmonary disease and healthy volunteers
}

\author{
Matthew Kennedy, ${ }^{1,2}$ Mohammadali Y Ramsheh, ${ }^{1}$ Caroline M L Williams, ${ }^{1}$ \\ Joss Auty, ${ }^{1}$ Koirobi Haldar, ${ }^{1}$ Mohamad Abdulwhhab, ${ }^{1}$ Christopher E Brightling, ${ }^{1,2}$ \\ Michael R Barer ${ }^{1,2}$
}

To cite: Kennedy M, Ramsheh MY, Williams CML, et al. Face mask sampling reveals antimicrobial resistance genes in exhaled aerosols from patients with chronic obstructive pulmonary disease and healthy volunteers. BMJ Open Resp Res 2018;5:e000321. doi:10.1136/ bmjresp-2018-000321

- Additional material is published online only. To view please visit the journal online (http://dx.doi.org/10.1136/ bmjresp-2018-000321).

Received 12 June 2018 Revised 13 August 2018

Check for updates

\section{(c) Author(s) (or their} employer(s)) 2018. Re-use permitted under CC BY-NC. No commercial re-use. See rights and permissions. Published by BMJ.

${ }^{1}$ Department of Infection, Immunity and Inflammation, University of Leicester, Leicester, UK

${ }^{2}$ Department of Clinical Microbiology, University Hospitals of Leicester, Leicester, UK

Correspondence to Dr Matthew Kennedy; mk526@le.ac.uk

\section{ABSTRACT}

Introduction The degree to which bacteria in the human respiratory tract are aerosolised by individuals is not established. Building on our experience sampling bacteria exhaled by individuals with pulmonary tuberculosis using face masks, we hypothesised that patients with conditions frequently treated with antimicrobials, such as chronic obstructive pulmonary disease (COPD), might exhale significant numbers of bacteria carrying antimicrobial resistance (AMR) genes and that this may constitute a previously undefined risk for the transmission of AMR. Methods Fifteen-minute mask samples were taken from 13 patients with COPD (five paired with contemporaneous sputum samples) and 10 healthy controls. DNA was extracted from cell pellets derived from gelatine filters mounted within the mask. Quantitative PCR analyses directed to the AMR encoding genes: blaTEM ( $\beta$-lactamase), ErmB (target methylation), mefA (macrolide efflux pump) and tet $M$ (tetracycline ribosomal protection protein) and six additional targets were investigated. Positive signals above control samples were obtained for all the listed genes; however, background signals from the gelatine precluded analysis of the additional targets. Results 9 patients with COPD (69\%), aerosolised cells containing, in order of prevalence, mefA, tetM, ErmB and blaTEM, while three healthy controls $(30 \%)$ gave weak positive signals including all targets except blaTEM. Maximum estimated copy numbers of AMR genes aerosolised per minute were mefA: 3010, tetM: 486, ErmB: 92 and blaTEM: 24. The profile of positive signals found in sputum was not concordant with that in aerosol in multiple instances.

Discussion We identified aerosolised AMR genes in patients repeatedly exposed to antimicrobials and in healthy volunteers at lower frequencies and levels. The discrepancies between paired samples add weight to the view that sputum content does not define aerosol content. Mask sampling is a simple approach yielding samples from all subjects and information distinct from sputum analysis. Our results raise the possibility that patient-generated aerosols may be a significant means of AMR dissemination that should be assessed further and that consideration be given to related control measures.

\section{Key messages}

Aerosols generated from the human respiratory tract are a potential source for the dissemination of antimicrobial resistance (AMR) genes.

Patients with and to a lesser extent, healthy individuals, aerosolise bacteria carrying high numbers of AMR genes (up to thousands/per minute) without exerting any special respiratory effort.

- We describe use of a simple face mask-based aerosol sampling system compatible with routine clinical practice with 23 individuals and demonstrate its utility to detect AMR genes by quantitative PCR.

\section{BACKGROUND}

The threat of antimicrobial resistance (AMR) in infectious diseases has been extensively documented. ${ }^{1-4}$ Available antimicrobial therapy for commonplace infections such as those affecting the lower respiratory tract may become greatly restricted, compromising clinical management. Chronic obstructive pulmonary disease (COPD) is a 'common, treatable respiratory disease characterized by persistent respiratory symptoms and airflow limitation that is due to airway and/or alveolar abnormalities. ${ }^{5}$ Patients frequently experience exacerbations in symptoms associated with the isolation of bacterial pathogens from their sputum for which they are given antibiotics.

Mortality associated with bacteria exhibiting AMR is increasingly observed in intensive care patients treated for exacerbations of COPD (EOCOPD $)^{6}$; risk factors for EOCOPD with AMR include previous antimicrobial therapy, prolonged or systemic corticosteroid therapy, previous intubation and advanced COPD with severe lung function impairment. ${ }^{7}$ 
We have been developing the use of face masks to sample exhaled patient aerosols. The approach has been used to detect Mycobacterium tuberculosis ${ }^{8}$ and has potential applications in diagnosis and in assessing patient infectiousness. During our studies on the microbiome associated with COPD, we have detected numerous AMR encoding sequences (manuscript in preparation). Based on these experiences, we speculated that patients with COPD might exhale bacteria carrying AMR genes. Exhaled bacteria, therefore, may represent a previously unassessed means of AMR dissemination for which control measures should be considered. Our principal aim here was to explore the feasibility of this sampling technique to detect the presence of AMR genes in expired aerosols. We report results of sampling from patients with stable COPD and from healthy volunteers.

\section{METHODS}

\section{Samples}

Between October and December 2016, samples were collected from 13 patients with COPD attending an advanced COPD outpatient clinic (OPC) at Glenfield Hospital, University Hospitals of Leicester.

\section{Sample collection}

Synthetic fibre single-use face mask (FFP1) (Moldex, Culver City, USA), were fitted with gelatine filters (Sartorius, Goettingen, Germany) mounted on locally manufactured metal holders (figure 1). Direct aerosol sampling took place in consultation rooms in the OPC. Patients were fitted with the mask, covering both nose and mouth; no contact was made between the face and the filter prior to sampling. Masks were worn for $15 \mathrm{~min}$ with no restrictions on talking or coughing. Details of recent exacerbation of symptoms and antimicrobial treatment were recorded. Those expectorating sputum provided samples (stored at $4^{\circ} \mathrm{C}$ for up to 72 hours prior to DNA extraction). After sampling, face masks were immediately replaced in double grip seal bags and stored at $4^{\circ} \mathrm{C}$. In healthy volunteers, face mask sampling was performed as mentioned above with volunteers asked to read a set text aloud for $15 \mathrm{~min}$.

\section{Face mask processing}

Face masks were processed within 24 hours of sampling. In a class 2 safety cabinet, gelatine filters were removed with forceps and placed into a $40 \mathrm{~mL}$ crystallising glass dish. Up to $2 \mathrm{~mL}$ of sterilised collagenase buffer $(50 \mu \mathrm{g} /$ $\mathrm{mL}$ collagenase A (COLLA-RO, Roche Sigma, UK), 50 $\mathrm{mM}$ N-Tris-methyl-2-aminoethanesulfonic acid, $0.36 \mathrm{mM}$ calcium chloride, $\mathrm{pH}=7.4$ ) was added. Covered dishes were placed on a heated block at $37^{\circ} \mathrm{C}$ for $15 \mathrm{~min}$ until the gelatine filters were digested. The lysates were pipetted into $2 \mathrm{~mL}$ screw cap microfuge tubes and centrifuged for $10 \mathrm{~min}$ at $15000 \times \mathrm{g}$. The DNA extract was obtained by

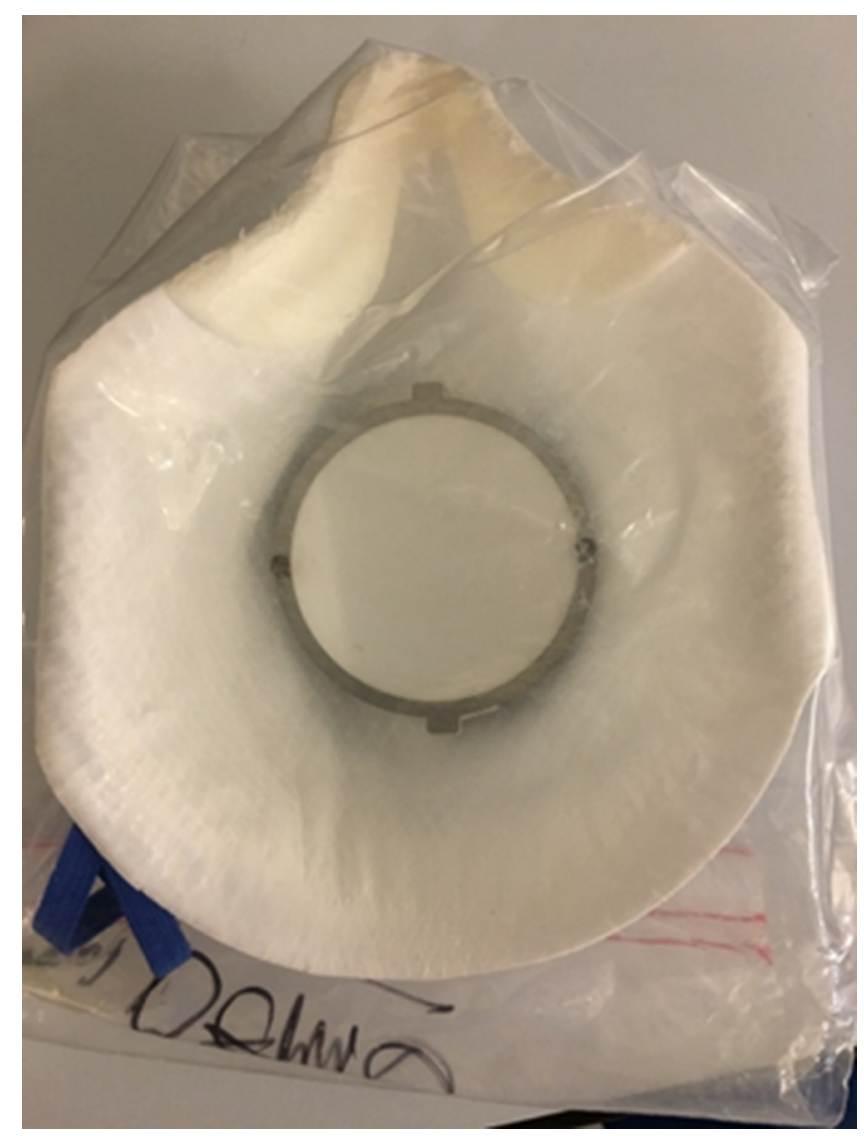

Figure 1 FFP1 face mask with gelatine filter.

centrifugation of the $2 \mathrm{~mL}$ lysate. The supernatants were discarded and the pellet stored at $-80^{\circ} \mathrm{C}$.

\section{DNA extraction}

The stored pellets were defrosted at room temperature and DNA was extracted using the QIAcube system and the Gram-positive protocol (QIAamp DNA mini kit, Qiagen, Valencia, USA). ${ }^{9}$ Sputum samples were weighed and homogenised with $1 \mathrm{~mL}$ of $0.1 \%$ dithiothreitol per gram prior to extraction. DNA extracted samples (100 $\mu \mathrm{L}$ ) were stored at $-20^{\circ} \mathrm{C}$ until quantitative PCR (qPCR) analysis.

\section{Quantitative PCR}

EOCOPD are routinely treated with $\beta$-lactams, macrolides or tetracyclines. On this basis and based on their detected prevalence in sputum studies (manuscript in preparation), $10 \mathrm{AMR}$ encoding genes were selected for analysis: $A m p C$, blaTEM, CfxA, FOX-5, PBP2X, ErmB, mefA, tet $M$, tet $A$ and AcrA-05. Up to $25 \mu \mathrm{L}$ PCR mixture of each reaction tube was prepared in $0.1 \mathrm{~mL}$ Rotor-Gene PCR tubes (QIAGEN, UK) containing $12.5 \mu \mathrm{L}$ of $2 \mathrm{X}$ SensiFAST SYBR No-ROX (BIOLINE, UK), $1 \mu \mathrm{L}$ of each $10 \mu \mathrm{M}$ forward and reverse primers (table 1; Integrated DNA Technologies), $1 \mu \mathrm{L}$ of DNA template and $9.5 \mu \mathrm{L}$ of molecular grade water; and run in technical triplicates on Rotor-Gene 6000 real-time DNA analysis system using 
Table 1 AMR targeted qPCR primers

\begin{tabular}{|c|c|c|}
\hline \multirow[b]{2}{*}{ AMR gene } & \multicolumn{2}{|l|}{ Oligonucleotide sequence } \\
\hline & Forward & Reverse \\
\hline blaTEM & AGCATCTTACGGATGGCATGA & TCCTCCGATCGTTGTCAGAAGT \\
\hline ErmB & TAAAGGGCATTTAACGACGAAACT & TTATACCTCTGTTTGTTAGGGAATTGAA \\
\hline mefA & CCGTAGCATTGGAACAGCTTTT & AAACGGAGTATAAGAGTGCTGCAA \\
\hline tetM & TAATATTGGAGTITAAGCTCATGTTGATG & ССTCTCTGACGTTCTAAAAGCGTATTAT \\
\hline AcrA-05 & CGTGCGCGAACGAACA & ACTTTGCGCGCCATCTTC \\
\hline AMPc-04 & TCCGGTGACCGCACAGA & CAGCACGCCGGTGAAAGT \\
\hline$c f x-A$ & TCATTCCTCGTTCAAGTTTTCAGA & TGCAGCACCAAGAGGAGATGT \\
\hline FOX-5 & GGTTTGCCGCTGCAGTTC & GCGGCCAGGTGACCAA \\
\hline PBP2X & TTTCATAAGTATCTGGACATGGAAGAA & CCAAAGGAAACTTGCTTGAGATTAG \\
\hline TetA-01 & GCTGTTTGTTCTGCCGGAAA & GGTTAAGTTCCTTGAACGCAAACT \\
\hline
\end{tabular}

AMR, antimicrobial resistance; qPCR, quantitative PCR.

Corbett PCR machine (Corbett Life Science, QIAGEN). The cycling conditions were as described by $\mathrm{Xu}$ et al. ${ }^{10}$ Pathogen-directed qPCR for Haemophilus influenzae and Staphylococcus aureus (SYBR green) and Moraxella catarrhalis, Pseudomonas aeruginosa and Streptococcus pneumoniae (Taqman) were performed in technical triplicates as previously described. ${ }^{11}$

Analyses for blaTEM, ErmB, mefA and tetMwere repeated using IDT gBlock standards (Integrated DNA Technologies) to enable quantification. Calibration curves converting cycling threshold $\left(C_{t}\right)$ values to gene copy numbers were generated as described by Gunawardana et al. ${ }^{12}$ A custom DNA oligomer-gBlock (Integrated DNA Technologies) was synthesised to span the region of the AMR genes covered by the forward and reverse primers for each of the four AMR genes assayed. Tenfold serial dilutions of these oligomers were used as qPCR standards. qPCR cycling conditions were modified for assay optimisation by increasing the annealing temperature to $63^{\circ} \mathrm{C}$ for 30 s. qPCR readings with an $\mathrm{R}_{2}>0.985$ and efficiency $\geq 85 \%$ were accepted. Blank gelatine filters due to their organic composition contained some intrinsic AMR genes (predominantly $\beta$-lactamase) which produced $\mathrm{C}_{\mathrm{t}}$ values ranging from 29 to 33 . However, these signals were at least three $C_{t}$ values above those obtained for the $10^{2}$ standard. The $\mathrm{C}_{\mathrm{t}}$ value of the $10^{2}$ standard was considered as the lower limit for detection. All technical replicates $(n=3)$ showed coefficients of variation below $10 \%$. Mask and sputum analyses are quoted as copies per mask and as copies per gram, respectively. The calculated total number of copies per face mask sample was derived from the calculated number of copies per qPCR reading (copy $/ \mu \mathrm{L}$ ) multiplied by the total volume of DNA extract $(200 \mu \mathrm{L})$.

\section{RESULTS}

Ten AMR genes were initially selected for analysis $(A m p C$, blaTEM, CfxA, FOX-5, PBP2X, ErmB, mefA, tetM, tetA and AcrA-05). Six of these (AcrA-05, AmpC, CfxA, FOX-5,
$P B P 2 X$, tetA) generated multiple amplicons in blank filter control samples. While melt curves consistent with the specific targets were observed within the mixtures, additional work to confirm their identities has not been undertaken. In contrast, blank filters produced no amplicons for the remaining four targets (ErmB, mefA, tetM and tet $A$ ) and single bands were obtained from positive samples on gel electrophoresis.

Thirteen 15 min mask aerosol and sputum samples collected contemporaneously from five patients were obtained and these were compared with mask samples from 10 healthy volunteers. Demographics of the subjects are shown in table 2 .

\section{Detection of AMR genes}

Positive detections in the mask and sputum samples are shown in figure 2. Nine patients with COPD (69\%) were found to have aerosolised cells containing AMR genes while only three $(30 \%)$ of the healthy volunteers did so. Of the patients with positive aerosols, one, three, two and one respectively aerosolised all four, three, two and one of the four target genes. Although samples from the four remaining patients showed some amplification, the $\mathrm{C}_{\mathrm{t}}$ values were below the established limit of detection. The frequency of positive mask samples was mefA>tet$M>$ ErmB $>$ blaTEM and this followed the relative frequency of positives observed in sputum. Although positives for three targets were found in the healthy volunteers, the frequencies were consistently lower than in the patient samples.

The quantitative results for COPD (aerosol and sputum for five subjects) and healthy volunteers (aerosol only) are shown in table 3. MefA was detected in all samples. In the paired sputum and aerosol analyses, four target positive results gave numerically higher copy numbers per gram of sputum than those per mask, while in five pairs the aerosol counts were higher. In two cases, the aerosol was positive and the sputum negative. We note that in patient 9 the mefA mask signal was higher while 


\begin{tabular}{|c|c|c|}
\hline Sample size & 13 & 10 \\
\hline Age (years) (SD) & $63.5(10.07)$ & Between 18 and $48^{*}$ \\
\hline Male (\%) & $5(38)$ & $2(20)$ \\
\hline Current smoker (\%) & $3(23)$ & NA \\
\hline $\mathrm{FEV}_{1} \%$ predicted & $30.6(12.6)$ & NA \\
\hline $\begin{array}{l}\text { Mean } \mathrm{FEV}_{1} / \mathrm{FVC} \text { ratio } \\
\text { (SD) }\end{array}$ & $31.4(7.7)$ & NA \\
\hline $\begin{array}{l}\text { Exacerbations per } \\
\text { year (SD) }\end{array}$ & $5.2(4.5)$ & NA \\
\hline Antimicrobials & & None within 6 months \\
\hline $\begin{array}{l}\text { Prophylactic } \\
\text { macrolides }\end{array}$ & 2 & NA \\
\hline Self-management & 10 & NA \\
\hline Amoxicillin† & 5 & NA \\
\hline Doxycycline & $\begin{array}{l}5 \text { (1 in } \\
\text { combination) }\end{array}$ & NA \\
\hline Levofloxacin & 1 & NA \\
\hline
\end{tabular}

*Individual ages of healthy volunteers not collected. †'Includes one on co-amoxiclav.

COPD, chronic obstructive pulmonary disease; FEV1, forced Eexpiratory Vvolume in $1 \mathrm{~s}$; FVC, forced vital capacity; NA, not applicable.

the tet $M$ signal showed the converse pattern. If the expelled aerosol reflects sputum content then we would expect the ratio between signals for these two targets to be the similar in both samples. The discrepant mefA/tet $M$ ratios observed between aerosol and sputum in patients 2 (1.1 vs 0.15$)$ and 9 (6.2 vs 0.02$)$ and the aerosol positive, sputum negative analyses argue against the view that aerosol is a direct sample of sputum (table 3 ).

\section{DISCUSSION}

We have detected four bacterial AMR encoding genes in aerosols generated by patients with COPD and, to a lesser extent, by healthy volunteers. To our knowledge, this is the first direct recognition that expired air is a potential means by which AMR genes may be disseminated. Our approach was applied in an outpatient setting and required only 15 min sampling without detailed instruction to the sampler or the subject.

While we initially selected 10 targets for analysis, we were only able to validate the assays for four of these in the mask sample system. This was due to intrinsic contamination of the gelatine filters we used to collect the samples. It is disconcerting that we obtained such high signals for multiple targets that we could not analyse our aerosol samples for six of our selected targets (AcrA-05, AmpC, CfxA, FOX-5, PBP2X, tetA).

\section{Presence of AMR genes}

We hypothesised that patients with COPD might aerosolise significant quantities of AMR genes as both frequent and prophylactic antimicrobial therapy in this group provides strong selection pressure for colonisation with resistant microorganisms. ${ }^{13}$ One or more AMR genes were identified in the aerosol samples from $69 \%$ of patients with COPD. Non-detection of AMR genes in the remaining four patient samples may reflect a lesser tendency to aerosolise bacteria from the lower airways in these individuals or absence of resistance. In the former regard, large differences in aerosolisation rates have been reported between individuals with smear positive tuberculosis, ${ }^{14}$ while in the latter, multiple complex factors beyond antimicrobial exposure contribute towards the evolution and persistence of AMR genes within the resistome. ${ }^{3}$

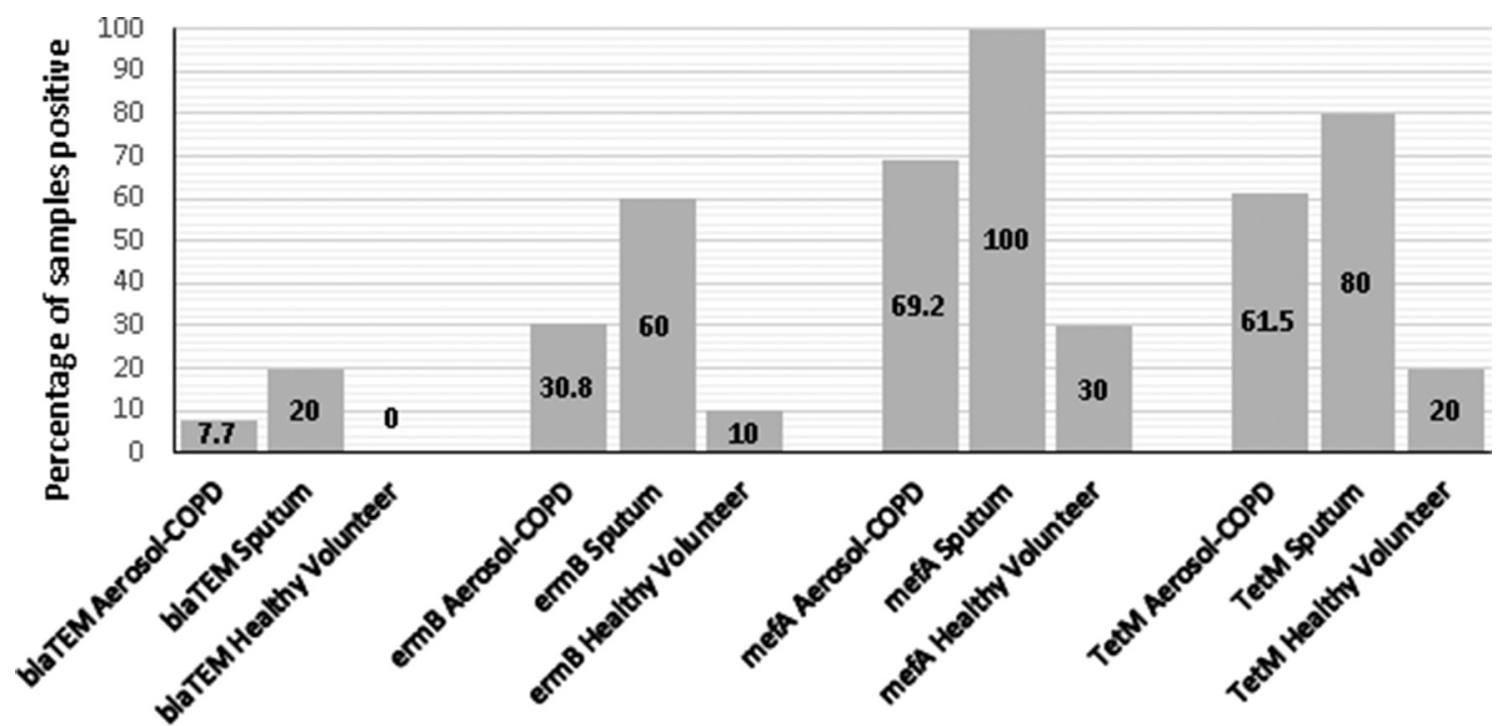

Sample typeand AMR gene

Figure 2 Prevalence of resistance genes in COPD aerosol, COPD sputum and healthy volunteer aerosol samples. AMR, antimicrobial resistance; COPD, chronic obstructive pulmonary disease. 
Table 3 Samples with positive qPCR signals obtained from mask and sputum samples

\begin{tabular}{|c|c|c|c|c|c|c|c|c|c|c|c|}
\hline \multicolumn{9}{|c|}{ Patients with COPD $(9 / 13)^{*}$} & \multicolumn{3}{|c|}{ HV $(3 / 10)^{*}$} \\
\hline \multicolumn{5}{|c|}{$\begin{array}{l}\text { Paired mask-ae (copies/mask) and sputum (sp) } \\
\text { samples }\end{array}$} & \multicolumn{4}{|c|}{ Mask only } & \multicolumn{3}{|c|}{ Mask only } \\
\hline 2 & 6 & 9 & 12 & 13 & 3 & 4 & 7 & 10 & 4 & 8 & 10 \\
\hline 114 & 1514 & 45159 & 8724 & 3574 & 254 & 120 & 478 & 5923 & 163 & 181 & 829 \\
\hline 6727 & 162 & 728 & 6253 & 74722 & & - & - & - & - & - & - \\
\hline 101 & 334 & 7296 & 365 & 1362 & 258 & $<$ & 308 & 247 & 134 & $<$ & 290 \\
\hline 45295 & $<$ & 37828 & $48 \dagger$ & 40590 & - & - & - & - & - & - & - \\
\hline$<$ & $<$ & $<$ & $<$ & 1375 & 239 & $<$ & 1379 & 273 & $<$ & $<$ & 1470 \\
\hline$<$ & $<$ & $<$ & $<$ & 17352 & - & - & - & - & $<$ & $<$ & $<$ \\
\hline$<$ & $<$ & $<$ & $<$ & $<$ & $<$ & $<$ & $<$ & 365 & $<$ & $<$ & $<$ \\
\hline$<$ & $<$ & $<$ & $<$ & $<$ & - & - & - & - & - & - & - \\
\hline 1.1 & 4.5 & 6.2 & 23.9 & 2.62 & - & - & - & - & - & - & - \\
\hline 0.15 & - & 0.02 & 56.7 & 1.84 & - & - & - & - & - & - & - \\
\hline Tet & Amox & Nil & Nil & Amox & Tet & Nil & Amox & $\begin{array}{l}\text { Co- } \\
\text { Amox }\end{array}$ & - & - & - \\
\hline Nil & $\mathrm{Mc}+\mathrm{Pa}$ & Nil & $\mathrm{Hi}$ & $\mathrm{Nil}$ & $\mathrm{Nil}$ & Nil & Nil & $\mathrm{Nil}$ & - & - & - \\
\hline
\end{tabular}

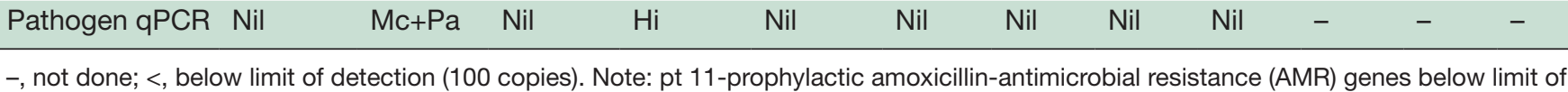
detection.

${ }^{*}$ Figures in parentheses show number of subjects positive/total number of subjects sampled.

$\dagger>100$ copies detected.

ae, mask aerosol sample (copies per mask); Amox, amoxicillin; COPD, chronic obstructive pulmonary disease; Co-Amox, co-amoxiclav; $\mathrm{HV}$, healthy volunteers; Hi, Haemophilus influenzae; Mc, Moraxella catarrhalis; Pa, Pseudomonas aeruginosa; Proph/SM, prophylaxis/selfmanagement; sp, sputum (copies per gram).Tet, tetracycline; qPCR, quantitative PCR;

MefA was identified in all of the positive COPD aerosol samples. This AMR gene is prevalent in streptococci ${ }^{15}$ and recognised as the most frequent macrolide resistance in $S$. pneumoniae, the PROTEKT study demonstrated $70.8 \%$ macrolide resistance in $S$. pneumoniae. ${ }^{16}$ Streptococci make a major contribution to the Firmicute signals obtained from lower respiratory tract samples but only $S$. pneumoniae is recognised as a commonly pathogenic in COPD. ${ }^{17} 18$ Interestingly, the pneumococcus was not detected in any of our aerosol samples here, indicating that the detected mefA signals presumably derived from other streptococci. It seems likely that the high prevalence of $m e f A$ in aerosols detected here, the natural transformability of $S$. pneumoniae ${ }^{19}$ and the high frequency of macrolide resistance in this pathogen are connected.

Among the three remaining targets tet $M$ was the most frequently detected; this has been reported as the most widely phylogenetically distributed of the AMR genes analysed here (table 4). In this pilot study we have not attempted to determine the bacterial hosts of the genes we detected. We note in table 4 that all four of our targets have been detected in Pseudomonas spp, all except mefA in Haemophilus spp and all except blaTEM in Streptococcus spp. While resistance in known pathogens clearly represents the greatest threat, our purpose here has been to add knowledge to understanding of AMR dissemination. The presence of these genes in aerosols clearly presents a previously undefined means of their dissemination whichever host the signals are derived from. Moreover, we have yet to determine the degree to which resistance determinants, particularly degradative enzymes, expressed in the lower respiratory microbiota other than recognised pathogens, may affect the outcome of therapy directed to apparently sensitive pathogens.

\section{Utility of mask sampling}

The present study builds on our experience in respiratory microbiology which has predominantly derived from sputum analyses. We have been surprised by the abundance of bacterial signals collected on face masks, notably the possibility that such collections may be of value in diagnosing and assessing infectivity in tuberculosis. ${ }^{8}$ Indeed, reviewing the data for patient 9 in table 3 , it appears that this patient with COPD exhaled over 3000 copies of mefA and 480 of tetM per minute. Both these AMR determinants have been reported to be encoded on Tn916-related transposons, ${ }^{20}{ }^{21}$ further emphasising the potential for their dissemination across strain and species barriers. It should also be noted that in contrast to the Cough Aerosol Sampling System (CASS) described by Fennelly and colleagues, ${ }^{22}$ subjects were not asked to perform specific respiratory efforts to obtain mask samples. Thus, our results represent AMR genes exhaled while subjects were breathing normally and may therefore represent natural dissemination rates.

Results from CASS studies have provided initial evidence that patient-produced aerosols are not a simple sample of 
Table 4 Reported family and genus level distribution of AMR genes detected in this study

\begin{tabular}{|c|c|}
\hline Gene & Reported distribution \\
\hline mefA & $\begin{array}{l}\text { Acinetobacter, Bacteroides, Citrobacter, } \\
\text { Clostridium, } \\
\text { Corynebacterium, Enterococcus, Enterobacter, } \\
\text { Escherichia, Fusobacterium, Gemella, Klebsiella, } \\
\text { Lactobacillus, Micrococcus, Morganella, } \\
\text { Neisseria, } \\
\text { Pantoea, Providencia, Proteus, Ralstonia, } \\
\text { Pseudomonas, Salmonella, Serratia, } \\
\text { Staphylococcus, Streptococcus, } \\
\text { Stenotrophomonas }{ }^{1531}\end{array}$ \\
\hline TetM & $\begin{array}{l}\text { Abiotrophia, Acinetobacter, Actinomyces, } \\
\text { Aerococcus, Aeromonas, Afipia, } \\
\text { Arthrobacter, Bacillus, Bacterionema, } \\
\text { Bacteroides, Bifidobacterium, Brachybacterium, } \\
\text { Catenibacterium, Clostridium, Corynebacterium, } \\
\text { Edwardsiella, } \\
\text { Eikenella, Enterobacter, Enterococcus, } \\
\text { Erysipelothrix, Escherichia, Eubacterium, } \\
\text { Flavobacterium, Fusobacterium, Gardnerella, } \\
\text { Gemella, Granulicatella, } \\
\text { Haemophilus, Kingella, Klebsiella, Kurthia, } \\
\text { Lactobacillus, Lactococcus, Listeria, } \\
\text { Microbacterium, Mycoplasma, Neisseria, } \\
\text { Paenibacillus, Pantoea, Pasteurella, } \\
\text { Peptostreptococcus, Photobacterium, Prevotella, } \\
\text { Pseudoalteromonas, } \\
\text { Pseudomonas, Ralstonia, Selenomonas, Serratia, } \\
\text { Shewanella, } \\
\text { Staphylococcus, Streptococcus, Streptomyces, } \\
\text { Ureaplasma, Veillonella, Vibrio }{ }^{15} 32\end{array}$ \\
\hline ermB & $\begin{array}{l}\text { Aggregatibacter, Acinetobacter, Aerococcus, } \\
\text { Arcanobacterium, Bacillus, Bacteroides, } \\
\text { Citrobacter, } \\
\text { Corynebacterium, Clostridium, Enterobacter, } \\
\text { Escherichia, Eubacterium, Enterococcus, } \\
\text { Fusobacterium, Gemella, Haemophilus, Klebsiella, } \\
\text { Lactobacillus, } \\
\text { Micrococcus, Neisseria, Pantoea, Pediococcus, } \\
\text { Peptostreptococcus, Porphyromonas, Proteus, } \\
\text { Pseudomonas, Ruminococcus, Rothia, Serratia, } \\
\text { Staphylococcus, Streptococcus, Treponema, } \\
\text { Wolinella }\end{array}$ \\
\hline blaTEM & $\begin{array}{l}\text { Enterobacteriaceae, Neisseriaceae, } \\
\text { Pseudomonas, Haemophilus }\end{array}$ \\
\hline
\end{tabular}

AMR, antimicrobial resistance.

sputum ${ }^{14}$ and there is further evidence for this here. As noted above, if aerosol is a direct sample of sputum, then the ratio between signals for different AMR genes should be the same in both. This was clearly not the case for two of the five paired samples shown in table 3 . While it is possible that the sampling procedure and processing of sputum and mask might bias the results, this effect would be expected to be consistent across all the samples and again this was not the case. We therefore suggest that the differing $m e f A / t e t M$ ratios observed provide further support to the view that aerosol is not a simple sample of sputum and that bacteria collected in masks have been selected by a process distinct from those present in sputum. One property potentially underpinning this is cell surface hydrophobicity, a property known to affect the potential of mycobacteria to enter into aerosols. ${ }^{23}$

\section{Limitations}

While this initial study on 23 individuals has illustrated the feasibility of the mask sampling approach, several aspects of our results should be interpreted with caution. In particular, our sample size was too small and demographic matching insufficient to allow formal comparisons of the AMR gene positive frequencies between our healthy and COPD subjects. A further important limitation was the presence of contaminating DNA in our gelatine filters which prevented analysis of 6 out of 10 of our initial targets. Gelatine is derived from animal collagen and is a by-product of the meat and leather industries. The tissues involved are certain to be contaminated with microbes, both during husbandry and in abattoirs. While our filters were guaranteed sterile by the manufacturers we know from this and other analyses that abundant bacterial DNA is present. Although further work will be needed to confirm the identity of the contaminating DNA the background signals we have detected raise further concern over the contribution of animal husbandry to the AMR problem. We have now developed a different sampling matrix that has no significant background and preliminary studies indicate that several of the targets excluded here can be detected in aerosols. A further shortcoming is that we have not optimised the efficiency of mask sampling by asking the patients to perform respiratory manoeuvres that maximise the collection yield of exhaled bacteria. Studies to identify the capacity of such manoeuvres to yield samples from different parts of the respiratory tract are in progress.

We have not identified the host organisms for the AMR genes studied here. This could be achieved with a metagenomic approach or by more limited sequencing studies but these were beyond the scope of this exploratory study.

Caution should be exercised in interpreting the low signals that were detected in many mask samples. However, confidence that these were true positives in the COPD subjects is reinforced by the detection of the same target in sputum and correspondence between high frequency of positives in the latter sample and detection in aerosols. We re-emphasise that we found no background positive signals for our target genes on blank filters. We note that free bacterial DNA may be present in aerosolised samples ${ }^{24}$ and that this would not have been detected by our cell pellet directed procedure.

\section{Infection prevention and control implications}

Although viral spread is generally regarded as the principal airborne infection hazard, many bacterial respiratory pathogens are transmitted by this route. ${ }^{25}$ Nosocomial 
outbreaks of resistant bacterial respiratory infections ${ }^{26}$ and influenza ${ }^{27}$ are well documented. Approaches to reduce both pathogen and AMR transmission via aerosol in healthcare and other setting are clearly desirable. The contribution of human-generated aerosols containing bacterial cells or free bacterial DNA towards the growing AMR crisis is currently undefined.

Gilbert $e t a l^{28}$ isolated and amplified ermF, ermX and tet $G$ genes from airborne samples within hospital rooms. The originating organism(s) were unidentified, but hypothesised to arise from the genome of unculturable bacteria. Air sampling of four Iranian hospitals revealed airborne $\beta$-lactamase-resistant bacteria harbouring $O X A$ 23 and $O X A-51$ genes associated with Acinetobacter spp. The authors suggested the potential role for of airborne bacteria in the transmission of drug-resistant nosocomial infections, with identification of dissemination sources important in reducing transmission within the healthcare setting. ${ }^{29}$ Aerosolisation of AMR genes from patients may contribute to the burden of AMR circulating in the environment, and the airborne route has been identified as a potential reservoir of AMR elements necessitating further surveillance studies. ${ }^{30}$

Our study has demonstrated that patients with COPD and healthy volunteers can be a source of aerosolised AMR genes; our limited study indicates that the former groups are a more abundant source. The AMR genes detected here are already widely disseminated and the clinical impact of their continued aerosol spread is probably small. However, the potential to spread AMR genes with a greater clinical and public health impact is clearly established. There is growing recognition of the likely healthcare-associated airborne spread of highly resistant opportunistic pathogens such as Burkholderia cepacia and Mycobacterium abscessus in vulnerable patient groups including those with cystic fibrosis. We suggest that the mask aerosol sampling system (MASS) used here provides an amenable approach to assessing the scale and importance of human-exhaled microbial hazards at both individual and population levels. Such information will inform appropriate control measures.

\section{CONCLUSION}

We have demonstrated that patients with COPD aerosolise bacteria carrying AMR genes at rates up to thousands of copies per minute without exerting special respiratory effort. The simple MASS we describe is readily applicable in clinical settings and could be used extensively to measure respiratory output of microbes. This approach has potential to enable better control of agents spread by the respiratory route and could contribute to limiting the spread of AMR.

Acknowledgements The authors are grateful to the Staff of Department of Infection, Inflammation and Immunity and Clinical research Staff of Leicester Respiratory Biomedical Research Unit, particularly Nicole Toms and Beverley Hargadon for their assistance in recruiting and consenting patients and Vijay Mistry for assistance with DNA extraction.
Contributors MK: study conceptualisation, data collection, laboratory processing of COPD and volunteer samples, data interpretation, statistical analysis and drafting of manuscript. MYR, CMLW and JA: assistance with laboratory processing of samples. MA: collection of volunteer samples and extraction of DNA. KH: assistance with laboratory processing of samples and manuscript review. CEB: project supervision. MRB: study conceptualisation and manuscript drafting and review.

Funding This work was supported by a grant from the Dowager Countess Eleanor Peel Trust and the UK MRC (MR/P023061/1).

Competing interests None declared.

Patient consent Obtained.

Ethics approval Ethical approval was obtained from the East Midlands Research Ethics Committee (REC) approval 08/H0406/189. Additionally, aerosol DNA extracts were available from 10 healthy volunteers previously recruited at the University of Leicester between September and October 2015 (departmental ethics committee approval: 2369-ma680-3i).

Provenance and peer review Not commissioned; externally peer reviewed.

Data sharing statement All data collected as part of this study and used to reach the above conclusions are included within this article and in the online supplementary material. Data displayed within this article are available upon request from MK.

Open access This is an open access article distributed in accordance with the Creative Commons Attribution Non Commercial (CC BY-NC 4.0) license, which permits others to distribute, remix, adapt, build upon this work non-commercially, and license their derivative works on different terms, provided the original work is properly cited, appropriate credit is given, any changes made indicated, and the use is non-commercial. See: http://creativecommons.org/licenses/by-nc/4.0/

\section{REFERENCES}

1. Davies J, Davies D. Origins and evolution of antibiotic resistance. Microbiol Mol Biol Rev 2010;74:417-33.

2. Dodds DR. Antibiotic resistance: a current epilogue. Biochem Pharmacol 2017;134:139-46.

3. Holmes $\mathrm{AH}$, Moore LS, Sundsfjord A, et al. Understanding the mechanisms and drivers of antimicrobial resistance. Lancet 2016;387:176-87.

4. Theuretzbacher $U$. Global antibacterial resistance: the never-ending story. J Glob Antimicrob Resist 2013;1:63-9.

5. Global Initiative for Chronic Obstructive Lung Disease. Pocket guide to copd diagnosis, management, and prevention: a Guide for Health Care Professionals. 2017.

6. Nseir S, Di Pompeo C, Cavestri B, et al. Multiple-drug-resistant bacteria in patients with severe acute exacerbation of chronic obstructive pulmonary disease: prevalence, risk factors, and outcome. Crit Care Med 2006;34:2959-66.

7. Nseir S, Ader F. Prevalence and outcome of severe chronic obstructive pulmonary disease exacerbations caused by multidrugresistant bacteria. Curr Opin Pulm Med 2008;14:95-100.

8. Williams CM, Cheah ES, Malkin J, et al. Face mask sampling for the detection of Mycobacterium tuberculosis in expelled aerosols. PLoS One 2014:9:1-7

9. Qiagen. QIAamp® DNA Mini and Blood Mini Handbook. 2010.

10. Xu L, Ouyang W, Qian Y, et al. High-throughput profiling of antibiotic resistance genes in drinking water treatment plants and distribution systems. Environ Pollut 2016;213:119-26.

11. Bafadhel M, McKenna S, Terry S, et al. Acute exacerbations of chronic obstructive pulmonary disease: identification of biologic clusters and their biomarkers. Am J Respir Crit Care Med 2011;184:662-71.

12. Gunawardana $M$, Chang $S$, Jimenez A, et al. Isolation of PCR quality microbial community DNA from heavily contaminated environments. J Microbiol Methods 2014;102:1-7.

13. Brill SE, Law M, El-Emir E, et al. Effects of different antibiotic classes on airway bacteria in stable COPD using culture and molecular techniques: a randomised controlled trial. Thorax 2015;70:930-8.

14. Jones-López EC, Namugga O, Mumbowa F, et al. Cough aerosols of Mycobacterium tuberculosis predict new infection: a household contact study. Am J Respir Crit Care Med 2013;187:1007-15.

15. van Hoek AHAM, Mevius D, Guerra B, et al. Acquired antibiotic resistance genes: an overview. Front Microbiol 2011;2:1-27.

16. Farrell DJ, Couturier C, Hryniewicz W. Distribution and antibacterial susceptibility of macrolide resistance genotypes in Streptococcus pneumoniae: PROTEKT Year 5 (2003-2004). Int J Antimicrob Agents 2008;31:245-9. 
17. Cameron SJ, Lewis KE, Huws SA, et al. Metagenomic sequencing of the chronic obstructive pulmonary disease upper bronchial tract microbiome reveals functional changes associated with disease severity. PLoS One 2016;11:1-16.

18. Cabrera-Rubio R, Garcia-Núñez M, Setó L, et al. Microbiome diversity in the bronchial tracts of patients with chronic obstructive pulmonary disease. J Clin Microbiol 2012;50:3562-8.

19. Santoro F, Vianna ME, Roberts AP. Variation on a theme; an overview of the Tn916/Tn1545 family of mobile genetic elements in the oral and nasopharyngeal streptococci. Front Microbiol 2014;5:1-10.

20. Domenech A, Ardanuy C, Balsalobre L, et al. Pneumococci can persistently colonize adult patients with chronic respiratory disease. J Clin Microbiol 2012;50:4047-53.

21. Calatayud L, Ardanuy C, Cercenado E, et al. Serotypes, clones, and mechanisms of resistance of Erythromycin-resistant streptococcus pneumoniae isolates collected in Spain. Antimicrob Agents Chemother 2007;51:3240-6.

22. Wainwright CE, France MW, O'Rourke P, et al. Cough-generated aerosols of Pseudomonas aeruginosa and other Gram-negative bacteria from patients with cystic fibrosis. Thorax 2009;64:926-31.

23. Jankute M, Nataraj V, Lee OY-C, et al. The role of hydrophobicity in tuberculosis evolution and pathogenicity. Sci Rep 2017;7:1-10.

24. Zhen H, Han T, Fennell DE, et al. Release of free DNA by membraneimpaired bacterial aerosols due to aerosolization and air sampling. Appl Environ Microbiol 2013;79:7780-9.

25. Tang JW, Li Y, Eames I, et al. Factors involved in the aerosol transmission of infection and control of ventilation in healthcare premises. J Hosp Infect 2006;64:100-14.
26. Weiss K, Restieri C, Gauthier R, et al A nosocomial outbreak of fluoroquinolone-resistant Streptococcus pneumoniae. Clin Infect Dis 2001;33:517-22.

27. Sartor C, Zandotti C, Romain F, et al. Disruption of services in an internal medicine unit due to a nosocomial influenza outbreak. Infect Control Hosp Epidemiol 2002;23:615-9.

28. Gilbert $Y$, Veillette $M$, Duchaine $C$. Airborne bacteria and antibiotic resistance genes in hospital rooms. Aerobiologia 2010;26:185-94.

29. Mirhoseini SH, Nikaeen M, Shamsizadeh Z, et al. Hospital air: a potential route for transmission of infections caused by $\beta$-lactamresistant bacteria. Am J Infect Control 2016;44:898-904.

30. Messi P, Sabia C, Anacarso I, et al. Prevalence of multi-drugresistant (MDR) bacteria in air samples from indoor and outdoor environments. Aerobiologia 2015;31:381-7.

31. Roberts M. 2016. Location of the various genes 14/2/2017 [cited 2017 19/09/2017]; Macrolide resistance gene database]. http:// faculty.washington.edu/marilynr/ermweb4.pdf

32. Roberts M. Mechanism of resistance for characterized tet and otr genes. Tetreacycline resistance genes 2016 [cited 2017 19/09/2017]; 13/7/2016:[Tetracycline resistance gene database]. http://faculty. washington.edu/marilynr/tetweb1.pdf

33. Salverda ML, De Visser JA, Barlow M. Natural evolution of TEM-1 $\beta$-lactamase: experimental reconstruction and clinical relevance. FEMS Microbiol Rev 2010;34:1015-36.

34. Schroeder MR, Stephens DS. Macrolide resistance in Streptococcus pneumoniae. Front Cell Infect Microbiol 2016;6:1-9. 